\title{
Disturbances on magnetotelluric data due to DC electrified railway: A case study from southeastern Brazil
}

\author{
Marcelo B. Pádua, Antonio L. Padilha, and Ícaro Vitorello \\ Instituto Nacional de Pesquisas Espaciais - INPE, C.P. 515, 12201-970 São José dos Campos, Brazil
}

(Received December 4, 2000; Revised October 4, 2001; Accepted October 16, 2001)

\begin{abstract}
Magnetotelluric (MT) soundings were carried out in the period range of 20 to $6000 \mathrm{~s}$ along profiles roughly orthogonal to the Campos do Jordão Railway (CJRW), in the Brazilian southeastern region. The profiles were located over two adjacent regions with contrasting conductivity, the conductive sedimentary region of the Taubaté Basin and the resistive crystalline region of the Serra da Mantiqueira. The railway operates with DC current that produces an intense electromagnetic noise but only during diurnal periods, being turned off at night. The objective of this study is to characterize the CJRW noise in order to verify its effect on MT parameters. It was inferred that the entire length of the Taubate Basin is probably affected by the noise, whereas in the crystalline terrains the noise reaches distances in the range of 76 to $126 \mathrm{~km}$. The electric channels show a strong dependence on geology which is suggestive of the potential application of the CJRW as a controlled source in geophysical studies. The data were processed with modern techniques presently available to the scientific community. Under the conditions of the present study, it was observed that the robust Single Station technique is as efficient as the robust Remote Reference to remove the kind of noise generated by the CJRW, an intense perturbation that affects only some welldefined portions of the time series. Finally, the analyses reaffirm the necessity of a careful choice of the station to be used as reference in the Remote Reference technique.
\end{abstract}

\section{Introduction}

Man-made electromagnetic noise has been rising continuously because of the increased dependence of humans on electricity. New techniques are thus required to eliminate this interference on geoelectric and geomagnetic measurements to obtain trustworthy results that can be used in understanding geophysical processes. The electromagnetic noise due to DC electrified railways has been studied in respect to the interference produced in magnetic observatories (Yanagihara, 1977) and in magnetotelluric (MT) soundings (Fontes, 1988; Egbert et al., 2000) because of the noise's long range (tens of kilometers) and strong signal screening effects. The conventional spectral analysis used to eliminate noise, based on least squares analyses (Sims et al., 1971), is not efficient in this case because the noise is coherent and irregular.

Modern techniques for optimal noise removal in MT studies include the use of remote reference fields and robust processing methods. The Remote Reference (RR) technique consists basically of simultaneous measurements at two or more stations and the use of the signal (normally the magnetic) from one of the stations to eliminate the noise in the other sites through spectral analyses (Gamble et al., 1979). The robust spectral analysis shows a relative insensibility to a moderate presence of noisy data, or data that do not fit the statistical models, and it acts gradually on these perturbations (Egbert and Booker, 1986; Chave et al., 1987; Larsen,

Copy right (c) The Society of Geomagnetism and Earth, Planetary and Space Sciences (SGEPSS); The Seismological Society of Japan; The Volcanological Society of Japan; The Geodetic Society of Japan; The Japanese Society for Planetary Sciences.
1989). Normally the two techniques are combined for better results in the MT response function determination (Jones et al., 1989). However, since it is not possible to carry out measurements without the presence of noise, it is almost impossible to demonstrate the efficacy of these techniques to filter out properly the electromagnetic noise.

The present paper describes results from MT soundings in the neighborhood of the Campos do Jordão Railway (CJRW) in southeastern Brazil. Some properties of the noise, such as the extent of the effects and attenuation features, are discussed for soundings over two regions with a very large contrast in conductivities (highly conductive sedimentary basin and highly resistive crystalline rocks). The CJRW provides a good laboratory to evaluate data processing techniques because train traffic is not intense and the railway is turned off at night for a long period (approximately $8 \mathrm{~h}$ ). It is then possible to compare results from data affected (diurnal) and not affected (nocturnal) by the CJRW noise. As an additional exercise, both datasets (diurnal and nocturnal) are used together to evaluate if a better statistics (a larger amount of data) is also able to minimize adequately the ERW noise.

\section{Local Geology}

The CJRW is located in the Paraíba Valley of the Brazilian southeastern region, crossing two areas with very distinct geology: the Serra da Mantiqueira and the Taubate Basin (Fig. 1). The Serra da Mantiqueira is part of a Precambrian complex composed of mylonite gneisses, blastomylonites, mylonites, banded gneisses, granitic gneisses, schists, quartzites, amphibolites, granites, pegmatites, 


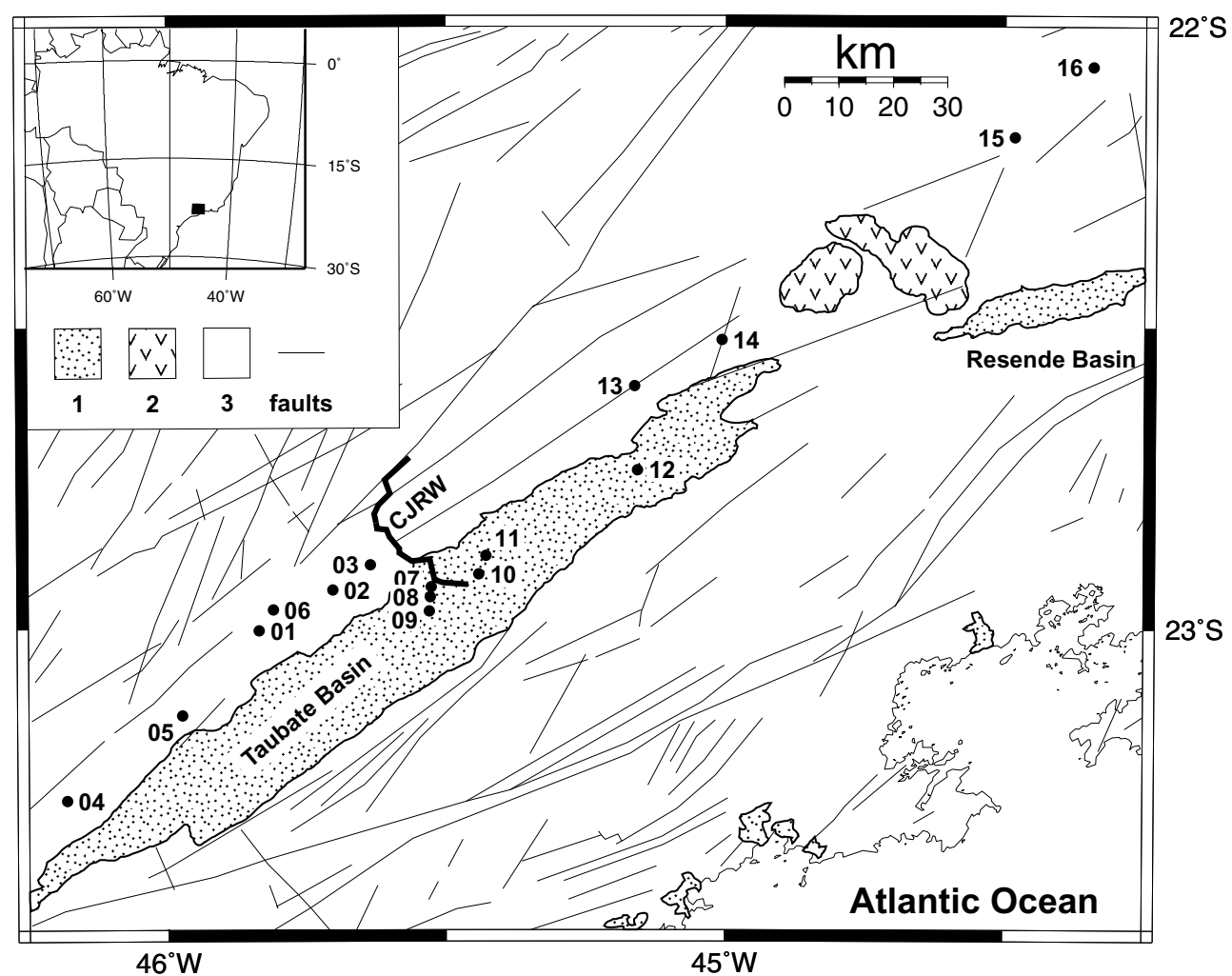

Fig. 1. Geologic map around the Taubaté Basin in the Brazilian southeastern region with the location of the MT stations (partially modified from RADAMBRASIL, 1983). 1) Cenozoic sedimentary cover, 2) Mesozoic/Cenozoic alkaline rocks, 3) Precambrian crystalline complex.

aplites, and migmatites. Diabase intrusions in the form of dikes and sills are common. Prominent and large NE$\mathrm{SW}$ trending transcurrent faults cut the crystalline complex deeply. AMT soundings have shown that these rocks can be represented by a surficial thin layer of relatively low resistivity (a tens-meters-thick zone of about $30 \mathrm{ohm} . \mathrm{m}$ ) over a thick and extremely resistive lower layer (about 10,000 ohm.m; Padilha and Vitorello, 1992).

The Taubaté Basin is characterized by an asymmetry between its lateral borders (a half-graben) and by small faults cutting the sediments. The NW margin, which generally has larger subsidence, is marked by contact faults between crystalline and sedimentary rocks, whereas the other margin exhibits a transgression of sediments over the basement. The basin is partially sectioned by four structural highs, compounding five subbasins, and filled with Upper EoceneOligocene sequences that include a basal pelitic material of lacustrine facies which grades to the top and laterally to a fluvial facies of sandy nature. Extensive geophysical soundings have characterized the sedimentary pile with a maximum thickness of $850 \mathrm{~m}$ (Marques, 1990) and a mean resistivity of 5 ohm.m (Padilha et al., 1991; Padilha and Vitorello, 1992).

\section{CJRW Noise}

There is a vast literature about noise in electromagnetic methods, as described in the reviews by Szarka (1988) and Junge (1996). Specifically, the noise generated by an ERW can be classified as active and irregular. The ERW's circuit consists basically of a rectifier substation, an overhead

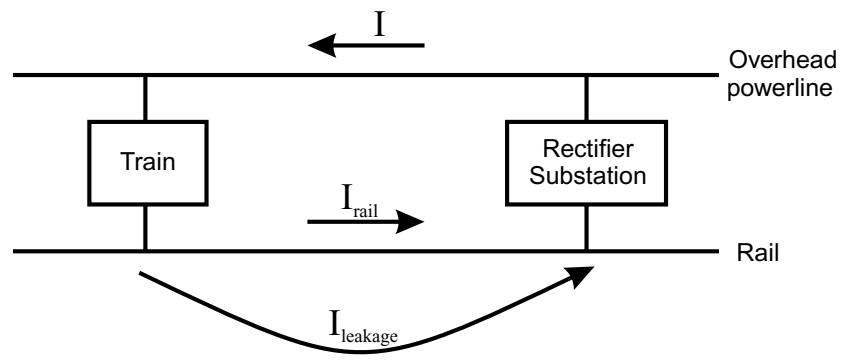

Fig. 2. Representation of the circuit of an electrified railway.

power line, a train engine, the rails and the soil to conduct the return current (Fig. 2). If the rails were perfectly isolated, all the current would return through them. In such an ideal situation, the electromagnetic (EM) field generated by the overhead power line would be cancelled by the field generated by the rails within a distance of a few kilometers. However, as the rails are not perfectly isolated, leakage occurs through the soil producing large EM fluctuations (Mikerina, 1962; Fraser and Ellyett, 1964; Jones and Kelly, 1966).

The CJRW is a DC electrified railway used mainly for tourism, running about 8 round trips per day from 6:00 to 19:20 LT, between the cities of Pindamonhangaba and Campos do Jordão. It is powered by two rectifier substations $(1500 \mathrm{~V}$ each) placed midway between these two towns. A single streetcar in Campos do Jordão also uses the CJRW line (10 journeys a day). 


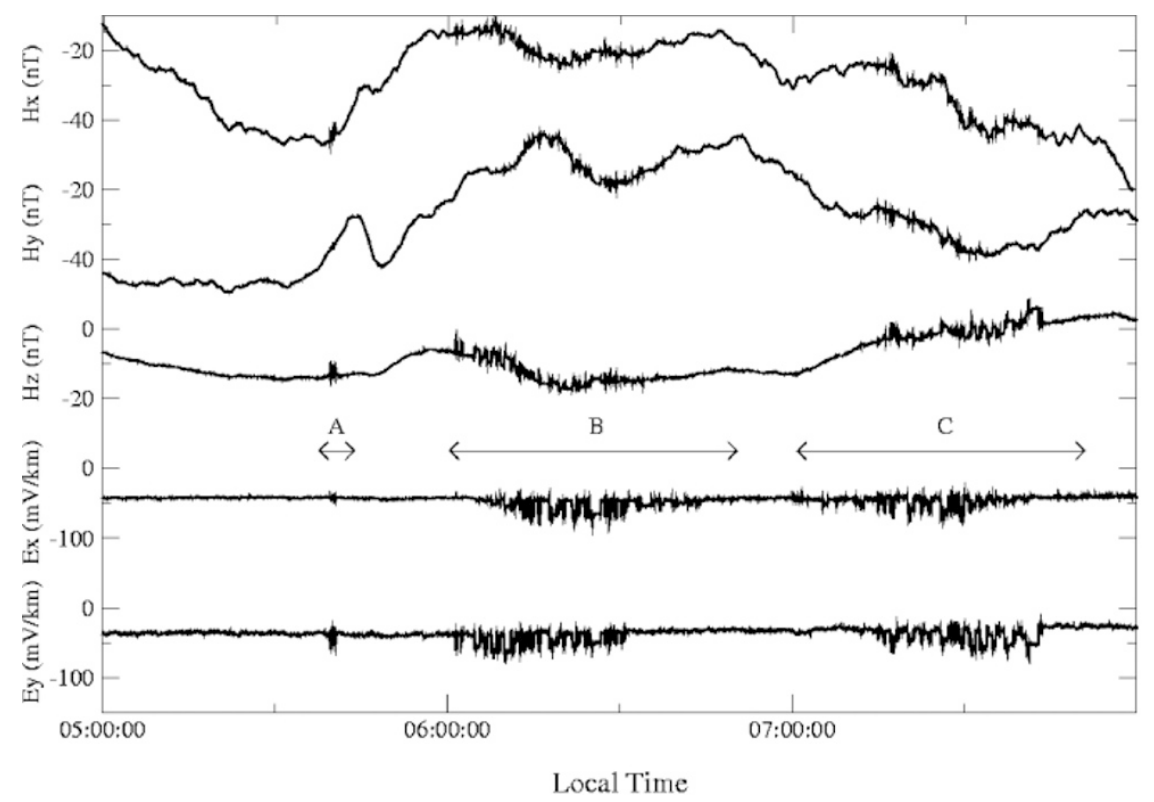

Fig. 3. Time series of EM components as recorded at station 08 on September 25, 1998 between 05:00 and 08:00 LT. Events A, B, and C are discussed in the text.

\subsection{Data acquisition}

The EM field components used in this study were recorded at the sixteen sites shown in Fig. 1 by commercial MT long period systems (LRMT; Phoenix Geophysics) operated in the period range of 20 to $6000 \mathrm{~s}$. The horizontal Ex (north geomagnetic) and Ey (east geomagnetic) telluric fields were acquired at each site by using a crossconfiguration with $150 \mathrm{~m}$ lengths. The three components of the magnetic field, $\mathrm{Hx}, \mathrm{Hy}$, and $\mathrm{Hz}$ (north, east, and vertical geomagnetic, respectively) were acquired with ring-core fluxgate sensors.

The data were collected along profiles: two inside and three outside the Taubaté Basin. Within the basin, station 12 is positioned over a structural high, where the sediment depth was estimated as $150 \mathrm{~m}$ by Marques (1990). Soundings 07,08 , and 09 are at the edge of another high, with estimated sediment thickness around $350 \mathrm{~m}$. Stations 10 and 11 are located on one of the subbasins and consequently are over a thicker sedimentary package of around $600 \mathrm{~m}$. Outside the basin, it is not possible to get reliable data far southwest of the basin limits due to cultural noise caused by the proximity of the large São Paulo city. Data from the profile to the northeast, composed by stations $13,14,15$, and 16 , will be discussed here in greater detail. Unfortunately, station 13 had operational problems and its data were not retrieved.

Figure 3 shows typical examples of distortions generated by the CJRW on the MT data. Burst-like structures are seen in the five EM components with three main events clearly discernible. Event A, just before 6 am, is possibly associated with train maneuvers in the train station. Event B, starting at $6 \mathrm{am}$, coincides with the first journey departing from Pindamonhangaba. Event $\mathrm{C}$, starting at $7 \mathrm{am}$, is the return trip. Visual inspection of the time series has indicated that all stations except 15 and 16 are contaminated by the CJRW noise.

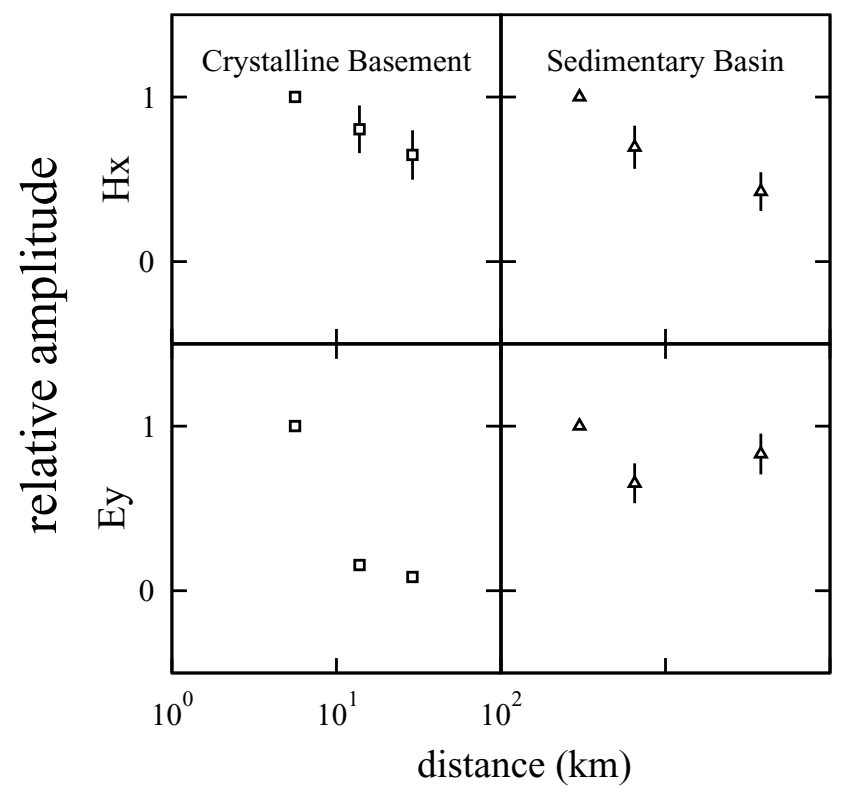

Fig. 4. Mean amplitude of normalized noise peaks simultaneously observed in the components Hx (upper graphs) and Ey (lower graphs). At left, stations 01,02, and 03; at right, stations 10,11, and 12. The abscissa refers to the distance from the CJRW.

\subsection{Qualitative analysis}

A qualitative evaluation of the attenuation of the CJRW noise as a function of the sounding distance was performed by choosing some well-defined peaks simultaneously observed at different sites. The amplitude of individual peaks was measured and normalized by the amplitude at the site closest to the CJRW in a given profile. Figure 4 shows the mean amplitude of normalized peaks for components $\mathrm{Hx}$ and Ey as observed along two profiles: one outside the basin (stations 01,02 , and 03 , normalized by station 03 ), and the 
other within the basin (stations 10, 11, and 12, normalized by station 10). In absolute values, magnetic amplitudes are roughly of the same order, but the electric amplitudes over the crystalline are much more intense.

In general, it is observed that the noise amplitude is reduced away from the CJRW both in the crystalline and in the basin as intuitively expected. These results are observed in the others channels and in other stations, not shown in Fig. 4. However, the amplitude of the electric field at the farthest station within the basin (station 12, located $38 \mathrm{~km}$ away from the CJRW) is an exception. It presents amplitudes higher than the ones observed at the intermediary station (site 11, at $6.5 \mathrm{~km}$ from the CJRW). This result can be explained if we take into account the fact that station 12 is located over a region with a much thinner sedimentary layer than that of station 11. Assuming that the electric noise over the basin has two components: a direct path within the basin and another from the crystalline basement, then it can be suggested that, in places where the sedimentary layer is thinner, there will be a noise amplification originated from the more intense crystalline electric component. The implied relationship between the electric field amplitude and the characteristics of the local geology suggests the possibility of the use of the CJRW noise as an artificial signal source for geophysical soundings, particularly within the basin. However, the evaluation of this suggestion is beyond the scope of the present paper.

\section{Estimation of MT Transfer Functions}

The profile composed by stations 14,15 , and 16 was chosen for the test of the techniques of robust processing and remote reference to remove the noise generated by the CJRW. A visual inspection of the time series has shown that the noise is clearly present in station 14 , strongly affecting the Ex channel but being tenuous in all the other channels. Simultaneous data from the three stations are available for a period of six consecutive days. They had been separated into three subsets (nocturnal, diurnal, and all data) and analyzed using the statistically robust code of Egbert and Booker (1986) to obtain estimates of apparent resistivity and phase for periods longer than $20 \mathrm{~s}$.

Figure 5 shows the final results of data processing of station 14 for the three data subsets, with the options of the single station (SS), remote reference with station 15 (RR15), or remote reference with station 16 (RR16). With rare exceptions, the data in the EyHx direction roughly give the same results in all analyses, confirming the low CJRW noise level in these components at the three sites. This result could be explained by the symmetry of the measuring coordinate axes in relation to the position of the CJRW. At long distances, the CJRW can be seen as an electric dipole running approximately parallel to the magnetic meridian. In such circumstances, the electric noise is heavily concentrated in the telluric channel parallel to this direction (Ex in our case; Goldstein and Strangway, 1975).

ExHy nocturnal data give similar results especially from SS and RR16 techniques. RR15 generates results a little more disturbed around $100 \mathrm{~s}$ and higher apparent resistivities (lower phases) at shorter periods. Surprisingly, the diurnal data do not show any clear improvement with the use of the remote reference. Again SS and RR16 are similar, except at periods shorter than $80 \mathrm{~s}$ when the transfer functions are also different from the nocturnal ones. RR15 is by far more contaminated than the other two approaches. The complete dataset reproduces the nocturnal results quite well (for SS and RR16) with the advantage of giving information at longer periods. Larger deviations are still present in RR15.

A further analysis was performed to evaluate the reason why RR15 gives results clearly more distorted than the other techniques. The robust processing scheme of Egbert (1997) based on multivariate statistical methods was used to estimate the background noise levels. Figure 6 shows the signal and incoherent noise power spectra in the magnetic channels of the three stations. A comparatively stronger noise is observed at station 15 , centered at periods around $500 \mathrm{~s}$. For the Hy component, the noise level is still strong at short periods. This incoherent noise is probably generated close to station 15. It makes this station unreliable for the RR technique, and explains the distortions observed in Fig. 5.

\section{Summary and Conclusions}

MT data from the Brazilian southeastern region show strong distortions generated by the CJRW. Due to its intensity, the noise is easily identified by the visual inspection of the time series, especially in the telluric channels. The extension of the affected area was determined through well defined events in the data. The entire region of the Taubate Basin is likely to be affected by the CJRW noise because at station 12 the CJRW noise is still intense. The basin does not have any other thick subbasin beyond that point and the noise over the crystalline complex is still strong at station 14 , which is close to the northeastern limit of the basin. In the crystalline terrains the noise extends beyond a minimum distance of $76 \mathrm{~km}$, which is from the CJRW to station 04, to a distance of less than $126 \mathrm{~km}$, which is the distance to station 15 , orthogonally to the railway tracks.

The features of the noise attenuation as a function of the distance from the CJRW, shown in Fig. 4, indicate an approximately exponential decrease of the amplitude in the magnetic channels. There is a strong dependence related to the local geology of distinct noise attenuation, registered by the electric channels. Such results indicate the potential application of the CJRW as an active controlled source. However, a larger volume of data would be necessary to evaluate this possibility, including detailed information about the characteristics of the electric currents produced by the train.

The application to our data of the processing techniques currently available to the scientific community has shown that, circumstantially, the robust SS is as efficient as the robust RR to remove the kind of noise found in the study area. This could be a specific feature of the analyzed data, characterized by an intense noise that affects only some welldefined portions of the time series, an ideal situation for a robust processing. A better statistics, represented by a larger volume of data with the use of the entire time series (nocturnal and diurnal), was also efficient in minimizing the noise effects. On the other hand, the distortions generated in the diurnal data of station 14 do not appear to be generated by a near-field source (phase values close to zero and appar- 


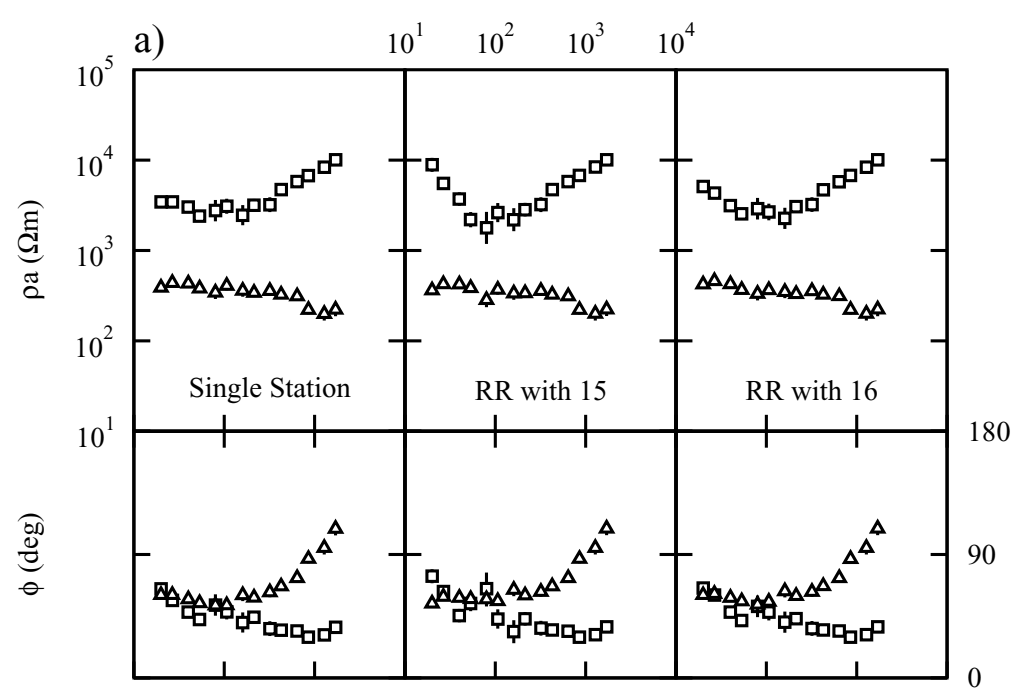

b)

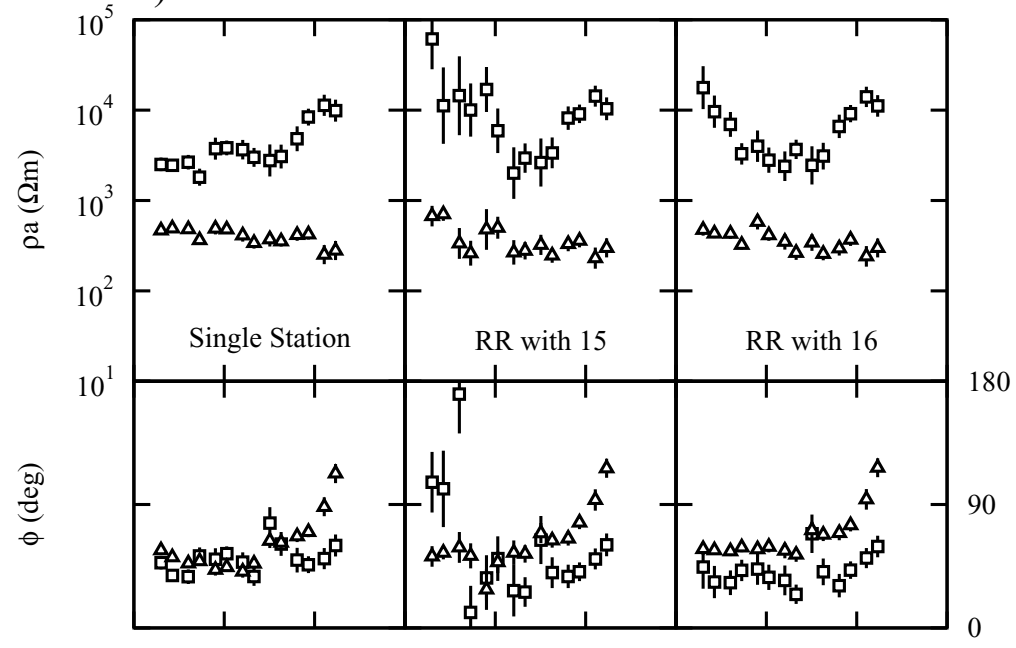

c)

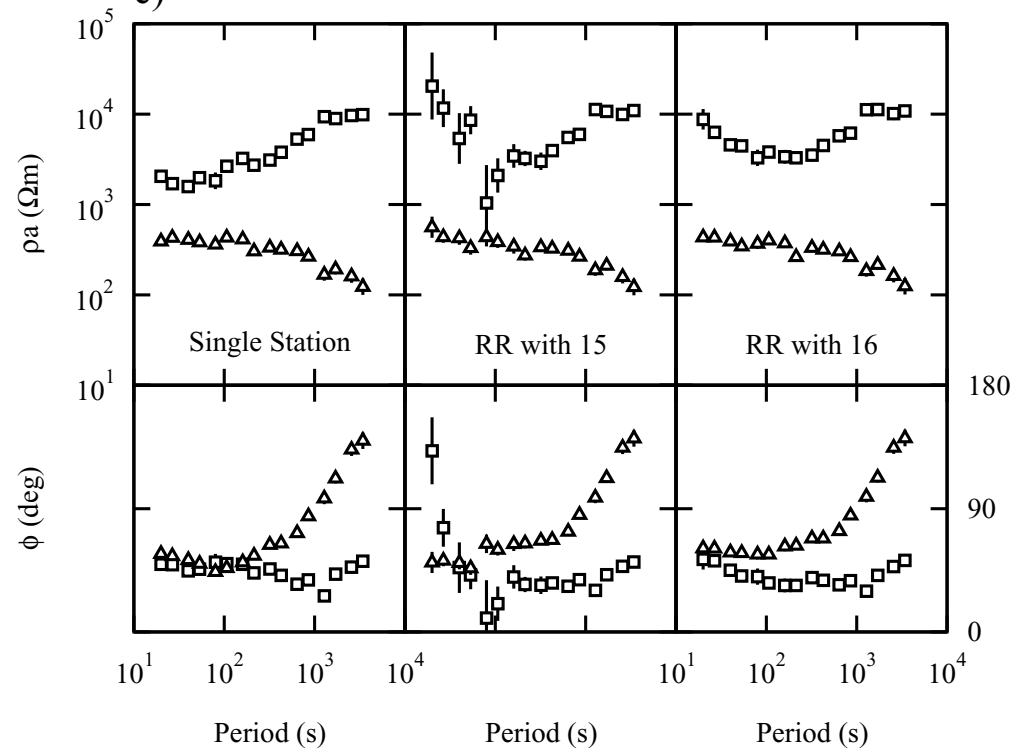

Fig. 5. Plots of apparent resistivity and phase data of station 14 for: (a) nocturnal data, (b) diurnal data, and (c) all data. Left plots are the single station determinations, center plots use station 15 as a remote reference, and right plots use station 16 as a remote reference. Error bars represent one standard deviation, squares stand for ExHy and triangles stand for EyHx. 


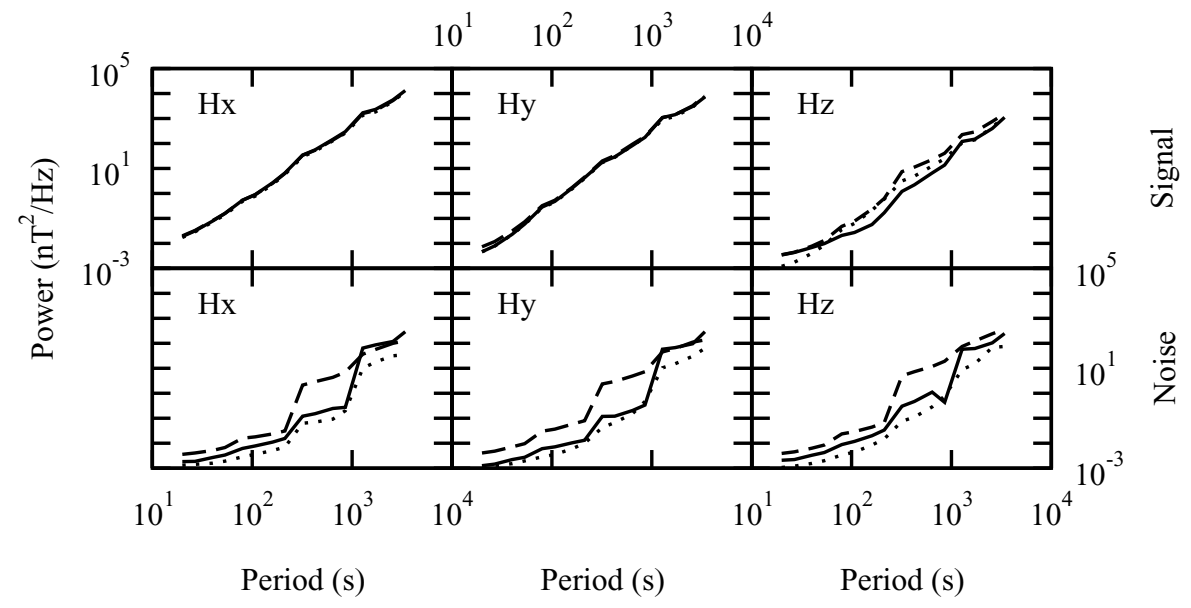

Fig. 6. Estimated signal and incoherent noise spectra computed for the magnetic channels from three stations of our survey. In all graphs solid lines give the spectrum for station 14, long dashes for station 15, and short dashes for station 16 . Upper pannels are for the signal spectra, lower pannels for the incoherent noise spectra.

ent resistivity curves with inclination near $45^{\circ}$; Qian and Pedersen, 1991). It can be speculated that the station 14 is located in an intermediate zone between near-field and farfield conditions.

A question that still needs to be elucidated, perhaps with other datasets, refers to the difference between SS and RR transfer functions at short periods. The application of another data processing scheme (Jones and Jödicke, 1984), not presented in this paper, supports the results from the robust SS analysis at these short periods. Also, our results reaffirm the necessity of scrutiny in the selection of the station to be used as reference in the RR technique. In the present study, the use of a station contaminated by local noise, not evident in the time series, gave results with a much lower quality compared to those from other analyses. Thus, one should not be reliant on a single station for RR.

Acknowledgments. This study was supported by research grants from FAPESP (93/0652-2 and 95/0687-4) and fellowships from CNPq (131366/98-0, 350683/94-8, and 351398/94-5). Thanks to $\mathrm{ON} / \mathrm{CNPq}$ for kindly loaning one of its long period MT systems, and to Fiona Simpson and Irina Popova for reviewing the submitted manuscript.

\section{References}

Chave, A. D., D. J. Thomson, and M. E. Ander, On the robust estimation of power spectra, coherences, and transfer functions, J. Geophys. Res., 92, 633-648, 1987.

Egbert, G. D., Robust multiple-station magnetotelluric data processing, Geophys. J. Int., 130, 475-496, 1997.

Egbert, G. D. and J. R. Booker, Robust estimation of geomagnetic transfer functions, Geophys. J. R. Astron. Soc., 87, 173-194, 1986.

Egbert, G. D., M. Eisel, O. S. Boyd, and H. F. Morrison, DC trains and Pc3s: Source effects in mid-latitude geomagnetic transfer functions, Geophys. Res. Lett., 27, 25-28, 2000.

Fontes, S. L., Electromagnetic induction studies in the Italian Alps, Ph.D. thesis, Univ. of Edinburgh, 351 pp., 1988.

Fraser, B. J. and C. D. Ellyett, Man-made magnetic micropulsations, J.
Geophys. Res., 69, 3603-3606, 1964.

Gamble, T. D., W. M. Goubau, and J. Clarke, Magnetotellurics with a remote magnetic reference, Geophysics, 44, 53-68, 1979.

Goldstein, M. A. and D. W. Strangway, Audio-frequency magnetotellurics with a grounded electric dipole source, Geophysics, 40, 669-683, 1975.

Jones, A. G. and H. Jödicke, Magnetotelluric transfer function estimation improvement by a coherence-based rejection technique, paper presented at 54th Annual International Meeting., Soc. of Expl. Geophys., Atlanta, Ga., Dec. 2-6, 1984.

Jones, F. W. and A. M. Kelly, Man-made telluric micropulsations, Can. J. Phys., 44, 3025-3031, 1966.

Jones, A. G., A. D. Chave, G. Egbert, D. Auld, and K. Bahr, A comparison of techniques for magnetotelluric response function estimation, $J$. Geophys. Res., 94, 14201-14213, 1989.

Junge, A., Characterization of and correction for cultural noise, Surv. Geophys., 17, 361-391, 1996.

Larsen, J. C., Transfer functions: smooth robust estimates by least-squares and remote reference methods, Geophys. J. Int., 99, 645-663, 1989.

Marques, A., Evolução tectono-sedimentar e perspectivas exploratórias da Bacia de Taubaté, São Paulo, Brasil, Bol. Geoc. Petrobrás, 4, 253-262, 1990.

Mikerina, N. V., The study of interference at the Voyeykovo magnetic observatory, Geomagn. Aeron., 2, 941-944, 1962.

Padilha, A. L. and Í. Vitorello, Investigações geoelétricas nas bacias de Taubaté, Volta Redonda e Resende, Exp. Abst. 37th Cong. Bras. Geologia, 2, 403-404, 1992.

Padilha, A. L., N. B. Trivedi, Í. Vitorello, and J. M. Da Costa, Geophysical constraints on tectonic models of the Taubaté Basin, southeastern Brazil, Tectonophys., 196, 157-172, 1991.

Qian, W. and L. B. Pedersen, Industrial interference magnetotellurics: an example from the Tangshan area, China, Geophysics, 56, 265-273, 1991.

RADAMBRASIL, Levantamento dos recursos minerais (Mapa geológico 1:1,000,000), RADAMBRASIL, Rio de Janeiro, 1983.

Sims, W. E., F. X. Bostick, Jr., and H. W. Smith, The estimation of magnetotelluric impedance tensor elements from measured data, Geophysics, 36, 938-942, 1971.

Szarka, L., Geophysics aspects of man-made electromagnetic noise in the earth: a review, Surv. Geophys., 9, 287-318, 1988.

Yanagihara, K., Magnetic field disturbance produced by electric railway, Mem. Kakioka Mag. Obs., 38, 17-34, 1977.

M. B. Pádua (e-mail: banik@dge.inpe.br), A. L. Padilha, and Í. Vitorello 